\title{
Challenge in Crop Production to Combat Complicated High Temperature Stresses
}

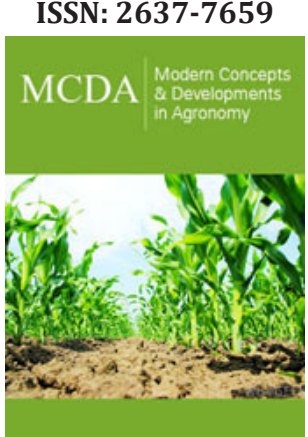

*Corresponding author: Yu Ling, College of Coastal Agricultural Sciences, Guangdong Ocean University, Zhanjiang, China

Submission: 㘹 February 01, 2021

Published: 想 February 19, 2021

Volume 8 - Issue 1

How to cite this article: Yujian Mo, Yu Ling. Challenge in Crop Production to Combat Complicated High Temperature Stresses. Mod Concep Dev Agrono. 8(1). MCDA. 000677. 2021 DOI: 10.31031/MCDA.2021.08.000677

Copyright@Yu Ling This article is distributed under the terms of the Creative Commons Attribution 4.0 International License, which permits unrestricted use and redistribution provided that the original author and source are credited.

\author{
Yujian Mo $^{1}$ and Yu Ling ${ }^{1,2 *}$ \\ ${ }^{1}$ College of Coastal Agricultural Sciences, Guangdong Ocean University, Zhanjiang, China \\ ${ }^{2}$ Shenzhen Institute of Guangdong Ocean University, China
}

\section{Abstract}

Global warming triggers complicated heat stresses to crop production on the Earth. Previously, most breeding programs focus on producing crop tolerate with short-term extreme high temperature stress. Hence, few recent studies have suggested that the plants adapting to extreme heat stress may be not always suitable for long-term mild high temperature stress. Therefor we propose challenges in crop production/ breeding which need to be conquered in the future.

\section{Introduction}

\section{Different kinds of high temperature stresses on the earth}

As we known that global warming results in happenings of extreme weathers, including extreme hot weathers. The mean temperatures anneal increase from 1880 to 2000 in general, especially in the duration of 1961-2000, within which there was significant drop in crop yields [1], though drop in yields resulted from complexed impacts in combination of temperature and other kinds of environmental factors.

In the case of temperature itself, the situation is also complicated, because there are several temperature-related variables, such as the anneal mean temperature, the maximum temperature, the frequency of extreme high temperature, and the high temperature duration. In southwest of China, it has been shown that all increase mildly during the period of 19751994, thus these factors increase sharply from 1995 to 2014. Further analysis revealed that the extreme temperature increases much faster than that of average temperature [2]. Supportively, observation from world-wide range also suggested that in addition to mean temperature, extreme high temperature days per year increased in most areas around the world in the past decades [3].

Challenge for crop production in resistant to different high temperature stresses
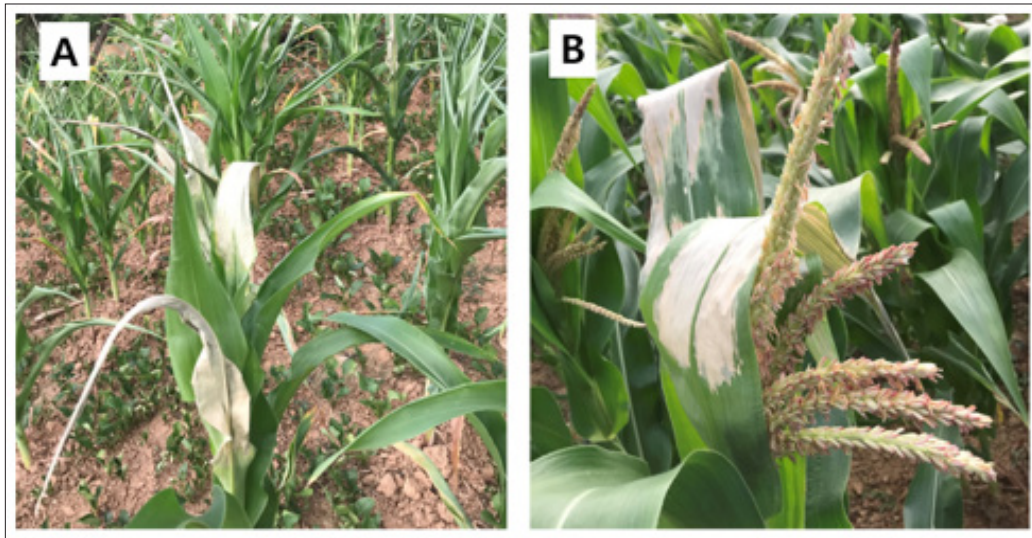

Figure 1: Heat-damage of maize plants.

A. Maize plants at vegetative stage,

B. Maize plants at reproductive stage with sterile stamens. 
In our experience there are different biases in research interests between different researchers. When we talk about global warming, ecologists are concerned more about the negative impact of long-term global warming on the stability of ecosystem, whereas scientists working on plants, including researchers in crop genetics and breeding, plant physiology and molecular biology, may be interested more in effects of severe short-term high temperature stress on crops, because extreme hot weathers happened occasionally may be disastrous to some crops. For example, there were 5 days with continuously extreme high temperature excessing $39{ }^{\circ} \mathrm{C}$ (from $5^{\text {th }}$ May 2020 to $9^{\text {th }}$ May, 2020) in a city, Baise, which is located at southwest of China. Consequently, maize plants at different developmental stages were suffered from significant heatdamage, with burned young leaves and sterile stamens (Figure 1).

Because of the fact that the disastrous damage of extreme hot weathers to crop production, in the past breeders may prefer to select crops that perform better in tolerating short-term extreme high temperature stress. Thus, to what extent this selection strategy benefits for crop tolerating complicated high temperature stress conditions in future is not clear yet. Because there are studies suggesting that plants may use different mechanisms to tolerate different kinds of high temperature stresses. In Rice, 'N22' was supposed to be a heat tolerant variety, whereas recent studies found that the trait of heat tolerant from N22 was only performed at basal heat tolerance. People found this rice variety was more sensitive to recurred high temperature stress than another rice variety 'Nipponbare', which has been considered to be heat sensitive variety [4]. More recently, another study demonstrated that the modern tomato cultivars lose the capacity to tolerate with heat priming (temperature increasing slowly) because of selection for genotypes those tolerate severe high temperature stress (sudden temperature elevation) [5].

These examples bring challenge for breeders who work in breeding heat-tolerant crops, because varieties with capacity in tolerating a kind of high temperature stress may be more fragile to other kinds of high temperature stresses.

\section{Perspective}

As global warming is going to continuously impose considerable impacts on the occurrence of heat events. In the future, to mitigate the impact of high temperatures to food security, we should continue to strengthen the basic research of plant response to distinguished high temperature stresses, uncover molecular mechanisms of plants in responding to varied high temperature stresses, and promote the research of heat-tolerant crop breeding in turn. In addition, targeted planting program should make according to different high temperature stresses predicted, from selection of crop species/genotypes to field managements.

\section{References}

1. Bita CE, Gerats T (2013) Plant tolerance to high temperature in a changing environment: scientific fundamentals and production of heat stress-tolerant crops. Front Plant Sci 4: 273.

2. Xue YT, Chen QL, Zhang JY, Huang P (2020) Trends in extreme high temperature at different altitudes of Southwest China during 19612014. Atmospheric and Oceanic Science Letters 13(5): 417-425.

3. Gornall J, Betts R, Burke E, Clark R, Camp J, et al. (2010) Implications of climate change for agricultural productivity in the early twenty-first century. Philos Trans R Soc Lond B Biol Sci 365(1554): 2973-2989.

4. Hu Y, Mesihovic A, Jimenez Gomez JM, Roth S, Gebhardt P, et al. (2020) Natural variation in HsfA2 pre-mRNA splicing is associated with changes in thermotolerance during tomato domestication. New Phytol 225(3): 1297-1310.

5. Lin MY, Chai KH, Ko SS, Kuang LY, Lur HS, et al. (2014) A positive feedback loop between HEAT SHOCK PROTEIN101 and HEAT STRESS-ASSOCIATED 32-KD PROTEIN modulates long-term acquired thermotolerance illustrating diverse heat stress responses in rice varieties. Plant Physiol 164(4): 2045-2053.

For possible submissions Click below: 